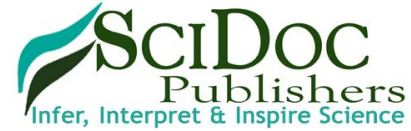

\section{Major Considerations and Success Score On the Angioplasty Procedure In a Cohort of Patients With Lower Heart Failure and Diabetes Mellitus}

Research Article

Gamero Osti $\mathrm{AV}^{1}$, Junior $\mathrm{JB}^{2}$, Novelli $\mathrm{D}^{3}$, Garcia Ramirez $\mathrm{AV}^{4}$, Filho IJZ $\mathrm{5}^{*}$

${ }^{1}$ Serviço de Hemodinâmica e Intervenções Cardiovasculares (INTERCOR), Hemodynamics and Cardiovascular Interventions Service, Hospital Santo Antônio, Sinop, MT, Brazil.

${ }^{2}$ Santa Casa de Misericórdia Hospital, Rua Fritz Jacob São José do Rio Preto, SP, Brazil.

${ }^{3}$ Di Marchioni Office, Rua José Polachini Sobrinho JD, Urano São José do Rio Preto, SP, Brazil.

${ }^{4}$ Brazilian Association of Nutrology (ABRAN), Brazilian Association of Nutrology, Catanduva, SP, Centro, Catanduva SP, Brazil.

${ }^{5}$ São Paulo State University (Unesp), Institute of Biosciences, Humanities and Exact Sciences (Ibilce), Campus São José do Rio Preto, SP, Brazil.

\title{
Abstract
}

Introduction: Cardiovascular diseases are the leading causes of death in the population. According to data from the World Health Organization of 2017, of the 21.7 million deaths from these diseases, more than ten million occur due to atherosclerotic coronary disease.

Objective: Therefore, the present study aimed to conduct a retrospective longitudinal and observational study on the clinical profile and response of the success analysis of patients who underwent angioplasty.

Methods: A total of 158 participants were submitted to eligibility analysis, followed by the rules STROBE (Strengthening the Reporting of Observational studies in Epidemiology), The present study followed a retrospective longitudinal and observational model on the analysis of the profile of patients who underwent angioplasty at Brazil. The predictors were: Cardiovascular Disease, Atherosclerosis, Angioplasty, Clinical Trial.

Results: The result of the Complete revascularization (CR) (YES: 62.7\%, NOT: 35.4\%) and the Success score was 95.6\%. Statistical correlation of regression between the continuous predictors and the response was demonstrated by means of the Matrix-Plot model graph. All analyzes presented statistical difference with $\mathrm{p}>0.05$, except between the predictors Gender $\mathrm{x}$ Complete revascularization, with $\mathrm{p}<0.05$.

Conclusion: In the present study, there were no influences of the continuous predictors such as age, $S A H, D M$ and Heart failure in relation to the success score and to complete revascularization, except for the predictor gender that showed to interfere in the final result.

Keywords: Cardiovascular Disease; Atherosclerosis; Angioplasty; Clinical Trial.

Abbreviations: STROBE: Strengthening the Reporting of Observational Studies in Epidemiology; CR: Complete Revascularization; CDs: Coronary Diseases; AMISST: Acute Myocardial Infarction with ST Segment Elevation; ECG: Electrocardiogram; SCA: Sudden Cardiac Arrest; CT: Computed Tomography; ROMICAT: Rule Out Myocardial Infarction by Computer Assisted Tomography; STEMI: ST-Elevation Myocardial Infarction.

\section{Introduction}

Cardiovascular diseases are the leading causes of death in the population. According to data from the World Health Organization of 2017, of the 21.7 million deaths from these diseases, more than ten million occur due to atherosclerotic coronary disease (ACD) [1]. ACD is the most common cause of mortality in developed countries $[1,2]$. Comparing Brazilian patients with stable ACD from 40 to 75 years per 1,000 inhabitants with those from European countries, it is noted that Brazil (58.4 $\%)$ is surpassed only by England (59.0\%) and Spain $(81.5 \%)[2,3]$. In Brazil, it is responsible for large numbers of deaths and health

\section{*Corresponding Author:}

Dr. Idiberto José Zotarelli Filho,

Professor, São Paulo State University (Unesp), Institute of Biosciences, Humanities and Exact Sciences (Ibilce), Campus São José do Rio Preto, SP, Brazil.

Tel: +55 (17) 4009-3939/+55(17) 8166-6537

E-mail:m.zotarelli@gmail.com

Received: April 17, 2018

Accepted: May 14, 2018

Published: May 16, 2018

Citation: Gamero Osti AV, Junior JB, Novelli D, Garcia Ramirez AV, Filho IJZ. Major Considerations and Success Score On the Angioplasty Procedure In a Cohort of Patients With Lower Heart Failure and Diabetes Mellitus. Int J Cardiol Res. 2018;5(1):95-100. doi: http://dx.doi.org/10.19070/2470-4563-1800016

Copyright: Filho IJZ ${ }^{\circ}$ 2018. This is an open-access article distributed under the terms of the Creative Commons Attribution License, which permits unrestricted use, distribution and reproduction in any medium, provided the original author and source are credited. 
care expenditures [2].

Among ACDs, highlight coronary diseases (CDs) resulting from occlusion or narrowing of the coronary arteries due to the formation of atherosclerotic plaques. The CDs, responsible for about 7.4 million deaths per year in Brazil [1-3], are associated with a set of risk factors, including advanced age, gender, smoking, obesity, hypertension, diabetes, genetic factors, hypercholesterolemia and sedentary lifestyle [2-4].

The pathophysiological manifestation of ACD involves coronary insufficiency, characterized by the imbalance between supply and consumption of oxygen at the myocyte level. Thus, the goal of treatment of stable angina depends on increased myocardial oxygen supply and reduced demand, which are closely related to contractility, left ventricular parietal stress, myocardial mass, and heart rate and post-load variations determined by blood pressure [4].

Within the therapeutic arsenal for the treatment of acute myocardial infarction with ST segment elevation (AMISST) to the electrocardiogram (ECG), primary percutaneous coronary intervention is the most important reperfusion strategy. However, its accomplishment within the deadlines defined in the evidence of the studies is a great challenge [5]. The typical clinical manifestation of chronic ACD is stable angina, characterized by pain or discomfort in the chest, epigastrium, mandible, shoulder, dorsum or upper limbs. It is usually described by the patient as tightness, oppression, constriction or weight, and is typically triggered or aggravated by physical activity or emotional stress and attenuated with rest and use of nitrates $[3,5]$.

The diagnosis of ACD is based on the association of clinical history and complementary examinations, since the majority of patients with ACD present normal physical examination. Thus, complete anamnesis and evaluation of personal and family history are fundamental $[7,8]$. The exams are used for the investigation of ACD and follow-up of risk factors, being useful in the diagnostic definition and assessment of its severity, including resting electrocardiogram, chest X-ray, simple ergometric test, echocardiography, myocardial scintigraphy, magnetic resonance imaging, coronary angiotomography and coronary angiography $[9,10]$.

The treatment of acute myocardial infarction with ST-segment elevation is consolidated in the trinomial thrombolysis chemistryprimary angioplasty-salvage angioplasty. Depending on the place of care and local conduct, these strategies work and lead to huge reductions in deaths and myocardial damage $[2,11]$. It is essential that the health system is organized to establish the best local strategy to obtain this enormous benefit of opening the artery responsible for the occluded infarct in the shortest time. The most used procedure for the treatment of coronary lesions is the angioplasty with stent implantation $[3,12]$.

Although there are advantages with this procedure, restenosis continues to be one of the main limiters of therapeutic success. It is known that inflammation, with accumulation of activated mononuclear cells, may contribute to the development of restenosis $[4,13]$. Primary angioplasty is the use of the balloon catheter with or without coronary stent implantation and without prior thrombolytic use, to mechanically restore the anterograde coronary flow. When available, it is the best option to obtain coronary reperfusion, if started up to $90 \mathrm{~min}$ after patient admission $[4,14]$.

Therefore, the present study aimed to conduct a retrospective longitudinal and observational study on the clinical profile and response of the success score analysis of patients who underwent angioplasty.

\section{Methods}

\section{Participants}

A total of 158 participants were submitted to eligibility analysis, followed by the rules STROBE (Strengthening the Reporting of Observational studies in Epidemiology), https://www.strobestatement.org/index.php?id=strobe-home.

\section{Study Design}

The present study followed a retrospective longitudinal and observational model on the analysis of the profile of patients who underwent angioplasty at Brazil. The predictors were: Cardiovascular disease. Atherosclerosis. Angioplasty. Clinical Trial.

\section{Statistical Analysis}

Statistical analysis of the data was performed and interpreted by the author of the present study. For data analysis a database was built in the Microsoft Excel spreadsheet which was exported to the Minitab 17 statistical program. A common descriptive statistical analysis and Anderson-Darling normality test were performed for all variables and controls, with reference $p>0.10$ as "normal". As there were continuous and categorical predictors (gender, age, SAH, DM and Heart Failure) and the response predictors (Success score and complete revascularization), linear regression and residual Durbin-Watson analysis were applied. For all linear regression tests, alpha level lower than 0.05 was adopted as significant. For Durbin-Watson residue analysis, the reference significance level was 0.05 , adopting as acceptable range of independence $1.46<\mathrm{dw}<1.63$ (according to the Durbin-Watson standard table, $\mathrm{dU}<\mathrm{dw}<4-\mathrm{dU}$ ), with two explanatory variables for sample size of $\mathrm{n}=158$.

\section{Results}

Based on the Table 1, found the profile of the demographic gender (-Male: $70.2 \%$, Female: $29.7 \%$, age $(65.9 \pm 11.9)$, SAH (YES: $77.8 \%$, NOT: $22.1 \%$ ), DM (YES: 34.8\%, NOT: $65.2 \%$ ), Heart Failure (NOT: $74.1 \% ; 35 \%<\mathrm{EF}<55 \%=19.6 \%$; $\mathrm{EF}<35 \%$ $=6.3)$.

Also found the profile of the predictors response, such as Clinical Condition with AMI SUPRA ST: 3.2\%, AMI: 13.9\%, Stable angina: 44.3\%, Asymptomatic: 11.4\%, Other: 7.5\%. Complete revascularization (CR) (YES: 62.7, NOT: 35.4); Success score was 95.6\%; Restenosis (NOT: 88.6\%; Conventional Stent: $6.3 \%$; Pharmacological Stent: 5.1\%). Complications after procedure (NOT: $88.0 \%$ ).

The results, Figure 1, of the statistical correlation of regression 
Table 1. Demographic data of continuous predictors, with amostral sample, $n=158$ patients.

\begin{tabular}{|c|c|}
\hline Continuous Predictors & Values in percentage $(\%)$ \\
\hline Gender & $\begin{array}{c}\text {-Male: } 70.2 \\
\text {-Female: } 29.7\end{array}$ \\
\hline Age & Median: $65.9 \pm 11.9$ \\
\hline SAH & $\begin{array}{l}\text { YES: } 77.8 \\
\text { NOT: } 22.1\end{array}$ \\
\hline $\mathrm{DM}$ & $\begin{array}{c}\text { YES: } 34.8 \\
\text { NOT: } 65.2\end{array}$ \\
\hline Heart Failure (HF) & $\begin{array}{c}\text { NOT: } 74.1 \\
35<\mathrm{EF}<55=19.6 \\
\mathrm{EF}<35=6.3\end{array}$ \\
\hline Clinical Condition & $\begin{array}{l}\text { 1. AMI SUPRA ST: } 3.2 \\
\text { 2. AMI: } 13.9 \\
\text { 3. Stable angina: } 44.3 \\
\text { 4. Asymptomatic: } 11.4 \\
\text { 6. Other: } 7.5\end{array}$ \\
\hline Complete revascularization (CR) & $\begin{array}{l}\text { YES: } 62.7 \\
\text { NOT: } 35.4\end{array}$ \\
\hline Results & Success: 95.6 \\
\hline Restenosis & $\begin{array}{c}\text { NOT: } 88.6 \\
\text { Conventional Stent: } 6.3 \\
\text { Pharmacological Stent: } 5.1\end{array}$ \\
\hline Complications after procedure & NOT: 88.0 \\
\hline
\end{tabular}

Figure 1. Graph matrix-Plot model showing the results of the regression analysis between continuous predictors and response, with $\mathrm{p}<0.05$ not significative.

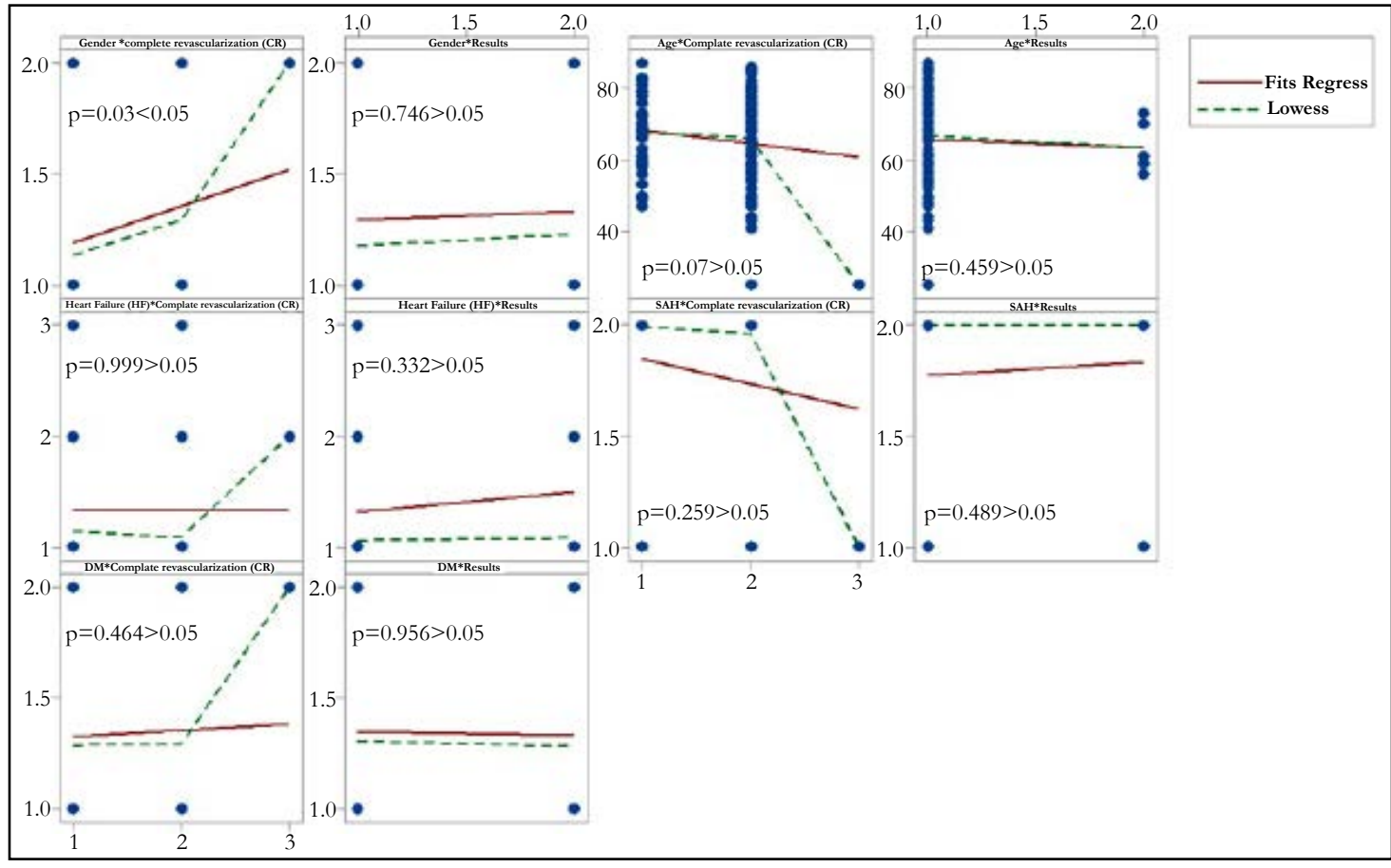

between the continuous predictors and the response was demonstrated by means of the Matrix-Plot model graph. All analyzes presented statistical difference with $\mathrm{p}>0.05$, except between the predictors Gender x Complete revascularization, with $\mathrm{p}<0.05$.

Furthermore, the results of the regression by Durbin-Watson residual analysis were confirmed in Figure 2, were within the acceptable range of independence $1.76<\mathrm{dw}<2.43$ (according to the Durbin-Watson standard table, $\mathrm{dU}<\mathrm{dw}<4-\mathrm{dU}$ ) with two explanatory variables and a sample size of $n=158$. Therefore, there was no relationship of dependence (significance) between the data analyzed. Thus, the results are confirmed by Figure 2, where the residues appear to follow a straight line. There is no evidence of discrepant points or unidentified variables; the residues appear to be randomly scattered around zero. There is 
Figure 2. Representative graphs showing the results of the Durbin-Watson residual analysis.
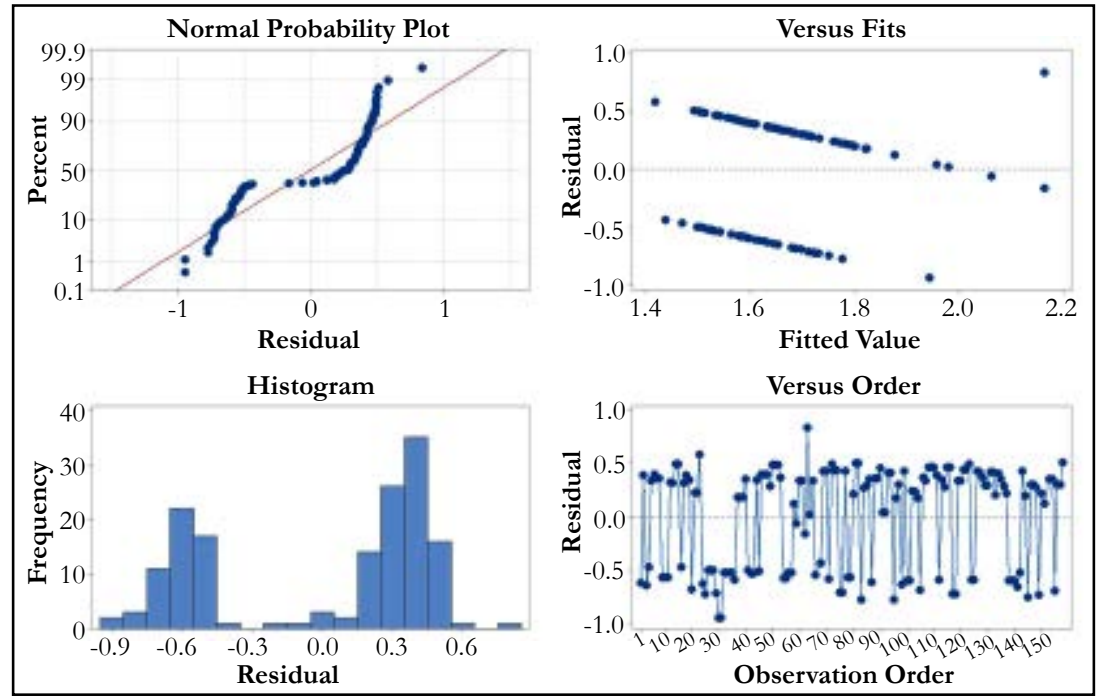

no evidence of non-constant variance, absent terms, discrepant points or influential points; the histogram does not follow a normal curve; the residues appear to be randomly scattered around zero. There is no evidence that the error is correlated with each other.

\section{Discussion}

This context, the results of the present study and in relation to other literary findings, chest pain suggestive of acute coronary insufficiency remains one of the most frequent complaints in individuals seeking emergency care [1-3]. Although very common, in general hospitals only a small part of them present acute coronary heart disease or another significant heart problem, leading to a large volume of unnecessary hospitalizations, with a high cost. Even so, the percentage of patients diagnosed with neglected AMISST is not negligible, largely due to the limitations of care protocols and diagnostic tools used [4-6].

It is not uncommon for patients who present with ACDs without ST elevation to have no electrocardiographic or laboratory abnormalities. In view of this, adequate assessment of the probability of atherosclerotic disease is fundamental [2]. The presence of one or more risk factors for coronary atherosclerotic disease, considerably increases the possibility of being the patient with an acute myocardial ischemic disease. Older age, male gender, family history of coronary disease, diabetes, hyperlipidemia, hypertension, smoking, chronic renal failure, previous infarction or atherosclerotic or carotid disease are widely known risk factors [3].

The initial diagnosis of ACDs with supra ST is temporally confounded with its treatment. Due to the severity and drama of the disease, diagnosis and treatment go hand in hand, with no loss of time [7-11]. The central symptom of sudden cardiac arrest (SCA) with supra ST is chest pain that lasts for more than 20 minutes, which does not subside with rest, nor with the use of nitrates [12-15]. As in cases of ACDs without supra ST, the pain is usually in oppression, it can radiate to one or both arms, jaw or nape. Also in these cases there are those who present atypical symptoms, usually elderly, women or diabetics [22].
The use of ATCCor in the evaluation of acute chest pain was initially investigated in different unicentric studies, demonstrating high sensitivity for detection of coronary stenosis, high negative predictive value to avoid acute coronary syndromes and moderate positive predictive value. Three large multicenter, controlled and randomized studies evaluated the use of ATCCor in chest pain treated in emergency units. A multicenter trial of 699 patients with low-risk chest pain for stratification strategies using coronary angiotomography (angio-CT) or myocardial computed tomography (CT) scintigraphy rest and stress [2].

Technical advances in computed tomography with multiple detectors allowed the assessment of coronary artery lumen noninvasively. The accuracy of coronary artery computed tomography (CT) angiography for the diagnosis of coronary stenosis, when compared to conventional angiography, is already well demonstrated, with a high negative predictive value [16-19]. Several studies have demonstrated that ATCCor is an important tool in the evaluation of patients with acute chest pain, especially in low and intermediate risk individuals, and is a safe method for the diagnosis of AMISST and reducing the rate and duration of hospital admission and, if necessary, the overall cost [19-21].

Further, the CT angiographic strategy reduced the time to diagnosis by $55.0 \%$ and the hospitalization costs by $41.0 \%$, without any difference in the rate of adverse events in relation to the scintigraphy strategy [2]. The purpose of the ACRIN-PA study was to evaluate the safety of CT angiography in the evaluation of patients with low and intermediate risk chest pain compared to the traditional approach. None of the patients with negative CT angiography had the primary endpoint analyzed, composed of cardiac death or infarction within the first 30 days after admission. In addition, patients in the angio-CT group had a higher rate of discharge from the emergency units $(49.6 \%$ vs. $22.7 \%)$ and fewer days of hospitalization (18 hours vs. 24.8 h, p <0.001), without significant differences in the incidence of coronary angiography or revascularization in 30 days.

The Rule Out Myocardial Infarction by Cardiac Computed Tomography II study (ROMICAT II) evaluated, in similar groups of patients, length of stay in the emergency and hospital costs. The study included 1,000 patients with a mean age of 54 years 
(46\% female). The time of hospital stay was significantly lower in patients stratified for ATCCor when compared to the traditional group $(23.2 \pm 37$ hours vs. $30.8 \pm 28$ hours, $\mathrm{p}=0.0002)$. The time to exclusion of the SIMI diagnosis was also lower in the group submitted to ATCCor $(17.2 \pm 24.6$ hours vs. $27.2 \pm 19.5$ hours, $\mathrm{p}<0.0001)$. Regarding safety goals, there was no significant difference between the groups [23, 24].

In the group stratified by ATCCor, there was a significant increase in patients who were discharged directly from the emergency room $(46.7 \%$ vs. $12.4 \%, \mathrm{p}=0.001)$, but the use of diagnostic tests was significantly higher in the group submitted to ATCCor (97\% vs. $82 \%, \mathrm{P}<0.001)$. Despite the higher cost associated with performing ATCCor and a trend towards more catheterizations and revascularizations, overall costs were similar between the two groups $(p=0.65)$ [24]. In summary, the use of coronary artery CT angiography is a safe strategy in the evaluation of patients with low and intermediate risk acute chest pain, reducing incidence, length of hospital stay, and probably costs. Its impact on the number of invasive procedures and revascularization rates are still conflicting $[25,26]$. Its application in patients with low/intermediate risk acute chest pain is recommended as an alternative to the ischemia test in several international guidelines.

In addition, the term SCA is used in situations in which the patient presents clinical and/or laboratory evidence of acute myocardial ischemia, caused by an imbalance between supply and demand of oxygen to the myocardium, and the main cause is the instability of an atherosclerotic plaque. SCA presents in two clinical forms: ST-segment elevation (SCACSST), or acute myocardial infarction with ST-segment elevation (STEMI), and ST-segment elevation non-ST-segment elevation (SCASSST) [3, 4, 28].

Patients with IAMSST should be treated immediately with primary PCI (within 90 mins of admission). Patients with a formal contraindication to thrombolytic therapy should be transferred for primary PCI within $12 \mathrm{~h}$ of symptom onset. The best option for reperfusion therapy in IAMSST is primary PCI. But the delay in achieving PCI reduces this advantage over thrombolytic therapy $[27,28]$. When this delay is greater than 60 minutes, the advantages equal. Thus, a strategy of pre-hospital chemical thrombolysis followed by planned PCI (for hemodynamically stable patients) or salvage PCI has shown results equivalent to or better than primary PCI for those patients presenting to the emergency department early [28].

Especially in those patients where primary PCI cannot be performed within 120 minutes of the first medical contact, or if chemical thrombolysis can be performed 60 minutes prior to PCI. Chemical thrombolysis still seems to play an important role in the treatment of patients with AMISST, especially in those who cannot reach a facility capable of delivering effective primary angioplasty rapidly. However, a treatment strategy based on invasive drug therapy depends on the adequate training of a team ready to administer pre-hospital thrombolytics and the efficiency of the care network, as determined and suggested in the US and Brazilian guidelines [28]. About the subject.

Over the past two decades, several studies have compared invasive strategy to conservative (or selective invasive) strategy [7-12]. In meta-analysis by Mehta et al., [25] (7 studies, 9212 patients), the implementation of an invasive strategy resulted in an $18 \%$ reduction in the relative risk of non-fatal infarction and death (14.4\% vs $12.2 \%$, OR, $0.82,95 \%$ CI $0.72-0.93, \mathrm{p}=0.001)$. In a meta-analysis with 7 studies and 8375 patients, Bavry et al., [26] revealed that the invasive strategy was associated with a $25.0 \%$ reduction in death $(4.9 \%$ vs $6.5 \%, \mathrm{RR}=0,95 \% \mathrm{CI} 0.63-0.90, \mathrm{p}=$ $0.001), 17.0 \%$ in non-fatal infarction rates $(7.6 \%$ vs $9.1 \%$, RR 0.83 CI $95 \% 0.72-0,96)$ and $31 \%$ in rehospitalization due to unstable angina (RR $0.6995 \%$ CI 0.65-0.74).

In a more recent meta-analysis from O'Donoughe et al., [26], 8 studies, $\mathrm{n}=10.150)$, it was demonstrated that the invasive strategy resulted in lower death rates, non-fatal infarction and rehospitalization due to angina after one year (21.1 vs $25.9 \%$, OR $0.78,95 \%$ CI 0.61-0.98), such benefits being restricted to patients with increased markers of myocardial necrosis [15]. With a longer-term segment, Fox et al., [27] (3 studies, 5467 patients) also revealed that patients submitted to the invasive strategy had a lower occurrence of death or infarction after 5 years $(14.7 \%$ vs $17.9 \%, \mathrm{RR}=0.81,95 \%$ CI $0.71-0.93, \mathrm{p}=0.002)$. The absolute risk reduction was more pronounced according to the severity of each patient $(2.0 \%$ in low risk patients, $3.8 \%$ in those at risk intermediate and $11.1 \%$ in high-risk individuals).

\section{Conclusion}

In the present study, there were no influences of the continuous predictors such as age, $S A H, D M$ and Heart failure in relation to the success score and to complete revascularization, except for the predictor gender that showed to interfere in the final result.

\section{Acknowledgements}

The work was supported by Serviço de Hemodinâmica e Intervenções Cardiovasculares (INTERCOR), Hospital Santo Antônio - Sinop, MT, Brazil.

\section{References}

[1]. World Health Organization WH, World Health Organization. The top 10 causes of death.

[2]. Ribeiro AL, Duncan BB, Brant LC, Lotufo PA, Mill JG, Barreto SM. Cardiovascular Health in Brazil: Trends and Perspectives. Circulation. 2016 Jan 26;133(4):422-33. PubMed PMID: 26811272.

[3]. Ference BA, Yoo W, Alesh I, Mahajan N, Mirowska KK, et al. Effect of long-term exposure to lower low-density lipoprotein cholesterol beginning early in life on the risk of coronary heart disease: a Mendelian randomization analysis. J Am Coll Cardiol. 2012 Dec 25;60(25):2631-9. PubMed PMID: 23083789.

[4]. Ference BA, Majeed F, Penumetcha R, Flack JM, Brook RD. Effect of naturally random allocation to lower low-density lipoprotein cholesterol on the risk of coronary heart disease mediated by polymorphisms in NPC1L1, HMGCR, or both: a $2 \times 2$ factorial Mendelian randomization study. J Am Coll Cardiol. 2015 Apr 21;65(15):1552-61. PubMed PMID: 25770315.

[5]. Quillard T, Araújo HA, Franck G, Shvartz E, Sukhova G, Libby P. TLR2 and neutrophils potentiate endothelial stress, apoptosis and detachment: implications for superficial erosion. Eur Heart J. 2015 Jun 7;36(22):1394-404. PubMed PMID: 25755115.

[6]. Berenson GS, Wattigney WA, Tracy RE, Newman III WP, et al. Atherosclerosis of the aorta and coronary arteries and cardiovascular risk factors in persons aged 6 to 30 years and studied at necropsy (The Bogalusa Heart Study). Am J Cardiol. 1992 Oct 1;70(9):851-8. PubMed PMID: 1529936.

[7]. Nordestgaard BG, Chapman MJ, Humphries SE, et al. Familial hypercholesterolaemia is underdiagnosed and undertreated in the general population: guidance for clinicians to prevent coronary heart disease: consensus statement of the European Atherosclerosis Society. Eur Heart J. 2013 Dec;34(45):3478-90a. PubMed PMID: 23956253.

[8]. Wiegman A, Gidding SS, Watts GF, et al. Familial hypercholesterolaemia 
in children and adolescents: gaining decades of life by optimizing detection and treatment. Eur Heart J. 2015 Sep 21;36(36):2425-37. PubMed PMID: 26009596.

[9]. Libby P. Mechanisms of acute coronary syndromes and their implications for therapy. N Engl J Med. 2013 May 23;368(21):2004-13. PubMed PMID: 23697515.

[10]. Ammirati E, Moroni F, Magnoni M, Camici PG. The role of T and B cells in human atherosclerosis and atherothrombosis. Clin Exp Immunol. 2015 Feb;179(2):173-87. PubMed PMID: 25352024.

[11]. Roffi M., Patrono C, Collet JP, Mueller C, Valgimigli M, Andreotti F, et al. 2015 ESC Guidelines for the management of acute coronary syndromes in patients presenting without persistent ST-segment elevation: Task Force for the Management of Acute Coronary Syndromes in Patients Presenting without Persistent ST-Segment Elevation of the European Society of Cardiology (ESC). Eur Heart J. 2016 Jan 14;37(3):267-315. PubMed PMID: 26320110 .

[12]. SAVICO (advanced life support in coronary disease). Reperfusion strategies. In Tavares, M et.al. São Paulo: Editora Manole Ltda; 2014. p. 53-62.

[13]. Reimer KA, Jennings RB. The" wavefront phenomenon" of myocardial ischemic cell death. II. Transmural progression of necrosis within the framework of ischemic bed size (myocardium at risk) and collateral flow. Lab Invest. 1979 Jun;40(6):633-44. PubMed PMID: 449273.

[14]. Gibson CM, Cannon CP, Piana RN, Breall JA, Sharaf B, et al. Angiographic predictors of reocclusion after thrombolysis: results from the Thrombolysis in Myocardial Infarction (TIMI) 4 trial. J Am Coll Cardiol. 1995 Mar 1;25(3):582-9. PubMed PMID: 7860900.

[15]. Denktas AE, Anderson HV, McCarthy J, Smalling RW. Total ischemic time: the correct focus of attention for optimal ST-segment elevation myocardial infarction care. JACC Cardiovasc Interv. 2011 Jun;4(6):599-604. PubMed PMID: 21700244

[16]. Gersh BJ, Stone GW, White HD, Holmes DR. Pharmacological facilitation of primary percutaneous coronary intervention for acute myocardial infarction: is the slope of the curve the shape of the future?. JAMA. 2005 Feb 23;293(8):979-86. PubMed PMID: 15728169.

[17]. Bonnefoy E, Lapostolle F, Leizorovicz A, Steg G, McFadden EP, et al. Primary angioplasty versus prehospital fibrinolysis in acute myocardial infarction: a randomised study. Lancet. 2002 Sep 14;360(9336):825-9. PubMed PMID: 12243916.

[18]. Westerhout CM, Bonnefoy E, Welsh RC, Steg PG, Boutitie F, Armstrong $\mathrm{PW}$. The influence of time from symptom onset and reperfusion strategy on 1-year survival in ST-elevation myocardial infarction: a pooled analysis of an early fibrinolytic strategy versus primary percutaneous coronary intervention from CAPTIM and WEST. Am Heart J. 2011 Feb;161(2):283-90. PubMed PMID: 21315210

[19]. TIMI IIIb Investigators. Effects of tissue plasminogen activator and a com- parison of early invasive and conservative strategies in unstable angina and non-Q-wave myocardial infarction: results of the TIMI IIIB trial. Circulation. 1994 Apr;89(4):1545-56. PubMed PMID: 8149520.

[20]. Boden WE, O'Rourke RA, Crawford MH, Blaustein AS, Deedwania PC, Zoble RG, et al. Outcomes in patients with acute non-Q-wave myocardial infarction randomly assigned to an invasive as compared with a conservative management strategy. N Engl J Med. 1998 Jun 18;338(25):1785-92. PubMed PMID: 9632444

[21]. Wallentin L, Lagerqvist B, Husted S, Kontny F, Ståhle E, et al. Outcome at 1 year after an invasive compared with a non-invasive strategy in unstable coronary-artery disease: the FRISC II invasive randomised trial. Lancet. 2000 Jul 1;356(9223):9-16. PubMed PMID: 10892758.

[22]. Cannon CP. TACTICS (Treat Angina With Aggrastat and Determine Cost of Therapy with an Invasive or Conservative Strategy)-Thrombolysis in Myocardial Infarction 18 Investigators. Comparison of early invasive and conservative strategies in patients with unstable coronary syndromes treated with glycoprotein IIb/IIIa inhibitor tirofiban. N Engl J Med. 2001;344:1879-87.

[23]. Spacek R, Widimský P, Straka Z. Value of first day angiography/angioplasty in evolving Non-ST segment elevation myocardial infarction: an open multicenter randomized trial. The VINO Study. Eur Heart J. 2002 Feb;23(3):2308. PubMed PMID: 11792138.

[24]. Fox K, Poole-Wilson PA, Henderson RA, Clayton TC, Chamberlain DA, et al. Interventional versus conservative treatment for patients with unstable angina oron-ST-elevation myocardial infarction: the British Heart Foundation RITA 3 randomised trial. Randomized Intervention Trial of unstable Angina. Lancet. 2002 Sep 7;360(9335):743-51. PubMed PMID: 12241831.

[25]. Mehta SR, Cannon CP, Fox KA, Wallentin L, Boden WE, et al. Routine vs selective invasive strategies in patients with acute coronary syndromes: a collaborative meta-analysis of randomized trials. JAMA. 2005 Jun 15;293(23):2908-17. PubMed PMID: 15956636.

[26]. Bavry AA, Kumbhani DJ, Rassi AN, Bhatt DL, Askari AT. Benefit of early invasive therapy in acute coronary syndromes: a meta-analysis of contemporary randomized clinical trials. J Am Coll Cardiol. 2006 Oct 3;48(7):131925. PubMed PMID: 17010789.

[27]. O’Donoghue M, Boden WE, Braunwald E, Cannon CP, et al. Early invasive vs conservative treatment strategies in women and men with unstable angina and non-ST-segment elevation myocardial infarction: a meta-analysis. JAMA. 2008 Jul 2;300(1):71-80. PubMed PMID: 18594042.

[28]. Fox KA, Clayton TC, Damman P, Pocock SJ, de Winter RJ, et al. Long-term outcome of a routine versus selective invasive strategy in patients with nonST-segment elevation acute coronary syndrome: a meta-analysis of individual patient data. J Am Coll Cardiol. 2010 Jun 1;55(22):2435-45. PubMed PMID: 20359842 